\title{
The Use of Classic Hallucinogens/Psychedelics in a Therapeutic Context: Healthcare Policy Opportunities and Challenges
}

This article was published in the following Dove Press journal: Risk Management and Healthcare Policy

\author{
Rafael Guimarães dos \\ Santos (iD) ${ }^{1-3}$ \\ José Carlos Bouso 1,3,4 \\ Juliana Mendes Rocha' \\ Giordano Novak Rossi (iD) \\ Jaime E Hallak ${ }^{1,2}$ \\ 'Department of Neurosciences and \\ Behavior, Ribeirão Preto Medical School, \\ University of São Paulo, Ribeirão Preto, \\ Brazil; ${ }^{2}$ National Institute of Science and \\ Technology - Translational Medicine, \\ Ribeirão Preto, Brazil; ${ }^{3}$ ICEERS \\ Foundation, International Center for \\ Ethnobotanical Education, Research and \\ Services, Barcelona, Spain; ${ }^{4}$ Medical \\ Anthropology Research Center, \\ Universitat Rovira i Virgili, Tarragona, \\ Spain
}

\begin{abstract}
Psychedelics or serotonergic hallucinogens are a group of substances that share the agonism of serotonergic $5-\mathrm{HT}_{2 \mathrm{~A}}$ receptors as their main mechanism of action. Its main effects include changes in perception, cognitive process, and mood. Despite being used for centuries by different cultures in ritual contexts, these substances have currently aroused the interest of science and industry for their promising antidepressant, anxiolytic, and antiaddictive effects. Considering this evidence, this article aims to explore some of the possible health policy challenges to integrate these therapeutic tools into broad and heterogeneous health systems. As a main benefit, these substances produce rapid and enduring effects with the administration of single or few doses, which could lead to new treatment possibilities for patients with severe mental disorders resistant to the usual medications. The main challenge is associated with the fact that these substances remain scheduled in most countries and are associated with social stigma related to their recreational use (especially LSD and psilocybin). This situation makes it exceedingly difficult to conduct clinical trials, although international conventions allow such research. Ethically, this could be interpreted as a violation of human rights since thousands of people are prevented from having access to possible benefits. Interestingly, ritual ayahuasca use is more acceptable to the public than the use of psilocybin-containing mushrooms or LSD. The controlled, clinical use of LSD and psilocybin seems to be less criticized and is being explored by the industry. Rigorous scientific evidence coupled with industrial interests (LSD and psilocybin), together with respect for traditional uses (ayahuasca) and international conventions, seems to be the best way for these drugs to be integrated into health systems in the next years. Which highlights the need for an urgent dialogue between science, health system, society, and politics.
\end{abstract}

Keywords: hallucinogens, psychedelics, healthcare

\section{Introduction}

\section{Background}

Psychedelics or serotonergic hallucinogens are a group of substances that have in common the agonism for serotonergic $5 \mathrm{HT}_{2 \mathrm{~A}}$ receptors as their main mechanism of action. ${ }^{1}$ These substances can be found in nature (such as psilocybin, present in mushrooms of the genus Psilocybe and many others; dimethyltryptamine/DMT, present in the botanical preparations ayahuasca and jurema; and mescaline, present in peyote and San Pedro cacti), or they can be of synthetic origins (such as the diethylamide of lysergic acid/LSD). ${ }^{2,3}$ Botanical psychedelics have been used for centuries as part of the traditional medicine of many cultures in the Americas. ${ }^{4-6}$ Mescaline has its

\footnotetext{
Correspondence: Rafael Guimarães dos Santos

Departamento de Neurociências eCiências do Comportamento, Faculdade de Medicina de Ribeirão Preto,

Universidade de São Paulo, Hospital das

Clínicas, Terceiro Andar, Av.

Bandeirantes, 3900, Ribeirão Preto, SP,

Brazil

Email banisteria@gmail.com
}

Risk Management and Healthcare Policy 202I:14 901-910

bmit your manuscrip

DovePress in $\square$ (c) (i) (5) 2021 dos Santos et al. This work is published and licensed by Dove Medical Press Limited. The full terms of this license are available at https://www.dovepress.com/ the work you hereby accept the Terms. Non-commercial uses of the work are permitted without any further permission from Dove Medical Press Limited, provided the work is properly attributed. For permission for commercial use of this work, please see paragraphs 4.2 and 5 of our Terms (https://www.dovepress.com/terms.php). 
traditional use based in northern Mexico (peyote) and Peru (San Pedro), and psilocybin (Psilocybe spp. mushrooms) in Central Mexico. ${ }^{5}$ DMT is the main hallucinogenic component present in jurema (traditionally used in Northeast Brazil) and ayahuasca (traditionally used in Northwestern Amazon in countries, such as Brazil, Peru, Ecuador, and Colombia). ${ }^{5}$

Psychedelics produce changes in sensory perception (mainly visual effects), cognitive processes (introspection, self-consciousness, mystical experiences, altered time passage) and mood (blissful state, euphoria, and joy). ${ }^{2,7}$ The intensity and nature of these effects are highly influenced by the set (personality and internal expectations of the subject), setting (environment in which the substance is used), and dosage. ${ }^{8}$ Subjects participating in clinical trials often describe mystical experiences and improved mood while under the effects of these substances. ${ }^{9-11}$ Although there is accumulating evidence that psychedelics are generally safe in humans, $7,10,12$ it is important to note that these substances can produce adverse effects and/or unpleasant experiences popularly known as "bad trips", which involve transitory anxious and psychotic symptoms, confusion, dissociation and depersonalization. ${ }^{7,8}$ Nevertheless, careful screening of volunteers and a supportive environment seem to reduce the occurrence and severity of these experience in controlled settings. ${ }^{7,13}$

\section{Therapeutic Properties}

Between the late 1950s and early 1970s several studies were conducted to investigate the possible therapeutic effects of psychedelics (especially LSD) in the treatment of anxiety, depression, and substance use disorders. ${ }^{8,13,14}$ Despite the promising results of these studies and the good safety profile of these drugs in controlled contexts, ${ }^{15}$ important methodological limitations in these studies (lack of placebo or control groups, absence of standardization in the monitoring of volunteers and interventions used) and the popularization of the recreational use of these drugs culminated in the prohibition of human studies until the early 1990s. ${ }^{2,8,13}$

In recent years, several research groups have been investigating the possible antidepressant, anxiolytic, and anti-addictive effects of psychedelics. Recent open-label studies showed that psilocybin reduced depressive and anxious symptoms in treatment-resistant depression $(\mathrm{TRD})^{16}$ and in major depressive disorder (MDD). ${ }^{17}$ Depression and anxiety symptoms were also reduced in controlled trials in terminal cancer patients. ${ }^{18,19}$ Psilocybin produced positive effects in open-label trials for the treatment of alcohol and tobacco dependence. ${ }^{20,21}$
Although there is less recent research with LSD, a recent meta-analysis of early studies in the 1960-70s provided evidence that it can be useful to treat of alcohol use disorder, ${ }^{22}$ and other studies indicate its possible anxiolytic properties in life-threatening diseases. ${ }^{23}$ Regarding ayahuasca, a controlled trial showed that it reduced panic-like and hopelessness symptoms in healthy volunteers. $^{24}$ Furthermore, an open-label $^{25}$ and a placebo-controlled trial ${ }^{26}$ showed that ayahuasca administration reduced depression, anxiety, and suicidality in patients with TRD. ${ }^{27,28}$

In most of these clinical trials single or few doses were administered, and the beneficial effects were fast-acting (hours/days) and enduring (weeks/months). ${ }^{17-21,23,25,26}$ Notably, all substances showed a good safety and tolerability profile, producing mostly mild/moderate and transient effects, such as vomiting and nausea, anxiety, confusion, and headache. ${ }^{17-21,23,25,26}$

In the 1980s, another type of serotonergic drugs with mindaltering and therapeutic properties appeared, the "entactogens" 29 These substances enhance empathy and emotional openness, and the most intensely studied drug of this class is MDMA (3,4-methylenedioxymethamphetamine), popularly known as "ecstasy". MDMA is being researched for the treatment of social anxiety in autistic adults, ${ }^{30}$ in the treatment of end-of-life anxiety (NCT00252174) and is being developed as a prescription medicine for the treatment of PostTraumatic Stress Disorder (PTSD). ${ }^{31}$ Both MDMA and psilocybin have been designated by the FDA as "breakthrough therapies" and in the case of MDMA both the FDA and the Israeli Agency of Medicines have authorized its use as a compassionate medicine. ${ }^{32}$ MDMA has different mechanisms of action from those of classic hallucinogens. Instead of agonism at cortical $5-\mathrm{HT}_{2 \mathrm{~A}}$ receptors, MDMA inhibits monoamine (serotonin $>$ norepinephrine $>$ dopamine) reuptake and enhances oxytocin release. ${ }^{33,34}$ The therapeutic effects of MDMA on PTSD seem to be related to memory reconsolidation and fear extinction. ${ }^{35}$ Although MDMA is not a truly "classical hallucinogen", it is of interest to mention briefly here because it is in Phase 3 of clinical trials for the treatment of PTSD and is also a scheduled substance. Therefore, the challenges related to its medical use are similar to those of classic hallucinogens.

\section{Mechanisms of Action}

The therapeutic effects of psychedelics are related primarily to their agonist action at the serotonergic receptor $5 \mathrm{HT}_{2 \mathrm{~A}}$, and to a minor extent at $5 \mathrm{HT}_{1 \mathrm{~A}}$ and $5 \mathrm{HT}_{2 \mathrm{C}}$ 
receptors. ${ }^{36,37}$ Agonists of $5 \mathrm{HT}_{1 \mathrm{~A}}$ receptors are thought to be responsible for passive adaptive response (tolerability to a source of stress), while $5 \mathrm{HT}_{2 \mathrm{~A}}$ agonists are thought to be responsible for the active adaptive response (dealing with the source of the stress actively). ${ }^{16}$ Considering that psychedelics are agonists of both receptors, the increase in overall adaptability could be related to their therapeutic effects. ${ }^{16}$ Furthermore, $5 \mathrm{HT}_{2 \mathrm{~A}}$ agonists also induce the release of glutamate, modulating the activation of the amygdala, hippocampus, and prefrontal cortex. ${ }^{38,39}$ The increase of glutamate in these brain areas also stimulates the synthesis of brain-derived neurotrophic factor (BDNF), increasing neuroplasticity. ${ }^{40,41}$ Reduced activity of the default mode network (DMN) and enhanced functional connectivity between otherwise distinct brain networks also indicate enhanced neuroplasticity induced by psychedelics. $^{10,42-44}$

Regarding ayahuasca, modulation of BDNF, cortisol, and inflammatory biomarkers seem to be related to its antidepressive effects in depressive patients. ${ }^{45-47}$ During an imagination task with the eyes closed, ayahuasca produced a brain activation pattern in occipital areas similar to the pattern observed when looking at an object with open eyes. ${ }^{48}$ This could be related to its therapeutic effects by giving a status of reality to inner experiences, such as biographical memories. $^{48}$

Moreover, LSD and psilocybin reduce the recognition of negative emotions through amygdala modulation, while increasing positive affect and mood. ${ }^{49}$ The anxiolytic and antidepressant effects reported in the literature seem to be related to this mechanism of action in brain areas related to emotional processing. ${ }^{49,50}$ Psychological mechanisms also seem to be involved in the therapeutic effects of hallucinogens. Decentering and mindfulness-related processes have been associated with positive therapeutic outcomes in studies of acute drug administration ${ }^{51-54}$ and in long-term users. ${ }^{55}$ Positive change in personality, such as increas in the traits of openness to experience and self-transcendence, is also related to the therapeutic effects of these compounds. ${ }^{7,56,57}$

It is still not clear what is the role of psychotherapy in clinical trials with psychedelics. Psychological interventions may or may not be used combined with psychedelics. In the open-label and controlled ayahuasca trials of ayahuasca for TRD, no psychotherapy was used, ${ }^{25,26}$ while in the open-label trials of psilocybin for TRD, ${ }^{16} \mathrm{MDD},{ }^{17}$ and alcohol ${ }^{20}$ and tobacco ${ }^{21}$ dependence, and in the $\operatorname{LSD}^{23}$ and psilocybin $^{18,19}$ trials for anxiety and depression in cancer patients, more elaborate techniques were used. Further research is needed to better understand the possible beneficial role of different types of psychotherapy in trials with psychedelics.

Considering the initial evidence presented of the potential therapeutic uses of psychedelics in mental health, we will now explore some of the possible and most relevant health policy opportunities and challenges that may be associated with the integration of the therapeutic use of these compounds in a broad and heterogeneous health system.

\section{Healthcare Policy Opportunities}

Most medications used for the treatment of psychiatric disorders, such as antidepressants and anxiolytics, are used daily and for longs periods (months to years). This increases the treatment costs for the individual and the health care system. The daily and prolonged use of these drugs is also associated with significant adverse effects, ${ }^{58}$ which also reduces treatment adherence. Moreover, most prescribed antidepressants and anxiolytics need several weeks to reach their therapeutic effects.

The paradigm of the treatments using hallucinogens/psychedelics is different since instead of being primarily pharmacologically oriented, it is both pharmacologically and psychologically oriented. Importantly, the usual method involves only one or few doses associated with a psychological treatment. For instance, in all current studies with these drugs only 1-3 doses are being used, and sometimes therapeutic effects are observed weeks to months afterwards. ${ }^{7,10,59}$ This is perhaps one of the most important benefits associated with these drugs since it would be cheaper for individuals and society in the long term. Although in the short term it will be necessary to invest time and resources in the treatment sessions (which may or may not include psychotherapeutic processes), only one or few treatment sessions would be performed, and benefits would last longer than current pharmacotherapy and/or standard psychotherapy. This could allow healthcare systems to prevent longterm costs. Furthermore, the good safety and tolerability of these treatments ${ }^{7,10}$ could increase treatment adherence and reduce social and individual costs in managing serious adverse effects.

Hallucinogens/psychedelics could also be one more opportunity for patients who do not respond to traditional/available medications. Treatment-resistant patients usually have tried at least two different medications (often more) without benefit and are a challenge to health professionals since treatment failure also increases symptoms overtime. Thus, any new treatment options that could 
have a significant impact on these individuals, their families, and society would be warranted. Chronic, treatment-resistant patients also have comorbid disorders and/ or diseases and low quality of life. By reducing part of the psychological suffering in terms of anxiety and depressive symptoms, psychedelics could indirectly reduce the overall disease burden and increase quality of life, especially in the long term.

Hallucinogens/psychedelics are also related to novel mechanisms of action in relation to traditional medications, which are often based on the monoaminergic imbalance theory. The modulation of cortical $5-\mathrm{HT}_{2 \mathrm{~A}}$ receptors and the subsequent increase in glutamatergic tone and the associated neuroplasticity are novel mechanisms of action. $^{7,41,60}$ The psychological effects of these drugs, which often include mystical experiences, increased empathy and sociality, ego dissolution, and increased acceptance, openness, and psychological flexibility, are also new therapeutic mechanisms considering that they are drug-induced and both acute and enduring, thus possibly enhancing the psychotherapeutic processes. Those new pharmacological and psychological perspectives are relevant to clinical practice and to psychopharmacological and psychological theories of psychiatric disorders.

Novel drugs and treatments could be derived from the use of these compounds in the future. ${ }^{61}$ These new treatments and advances could not only reduce social and individual disease-related burden by treating symptoms but also could prevent the development of psychiatric disorders. Indeed, populational studies did not find associations between psychedelics and mental health problems in most users, ${ }^{22,62}$ but did find that their use was associated with some mental health benefits. ${ }^{63-65}$

Similar advances are currently being observed with the use of the N-methyl-D-aspartate (NMDA) glutamate receptor antagonist ketamine in TRD. Ketamine also has psychedelic/hallucinogenic effects and induces fast and enduring antidepressant effects. ${ }^{66}$ However, the prolonged safety of ketamine is still poorly investigated, and this drug has potential for tolerance (resulting in increasing dosing and toxicity), abuse/dependence (increased by tolerance), and bladder toxicity. ${ }^{67}$ Such effects are not observed with classic psychedelics/hallucinogens. Regarding tolerance, although LSD and psilocybin induce a fast (and cross-) tolerance with repeated doing (with the possible exception of ayahuasca/DMT ${ }^{68}$ ) since their effects are prolonged with few doses there is no need to increase those doses. Besides, as previously mentioned, only few doses are usually used in current studies. Psychedelics/hallucinogens do not have a high abuse potential, and in controlled trials any such effects are reduced by using few doses. Previous observational studies with ritual ayahuasca users reported absence of social and psychological measures associated with drug abuse/ dependence. Instead, significant reductions in previous drug use/problems were observed. ${ }^{69}$

The social contexts and culturally mediated effects related to some of these drugs are also relevant in discussing the opportunities and benefits offered by them. In the case of ayahuasca, its traditional indigenous and syncretic religious use is often related to increases in social bonds and improvements in community health. ${ }^{70-74}$ Ayahuasca is usually used in group ceremonies or sessions, and previous studies among ritual users have observed improvements in mental health measures including reduced anxiety and depression, less use of prescription medications, better quality of life, psychosocial adjustment, stress coping strategies, and indicators of perceived social support. ${ }^{63,64}$ In these traditional contexts, ayahuasca is already a medicine, although it is important to acknowledge that the conceptions of diseases and their treatments are often quite different between traditional and non-traditional users. ${ }^{72,73}$ For instance, indigenous and syncretic religious users often have different worldviews and perspectives on health, which are also different for less religiously/ritually inspired users. In any case, it is quite interesting that ayahuasca is almost always used ritually and in groups, be it in the remote Amazonian tribes or in big urban centers.

In this sense, ayahuasca is different of other classic hallucinogens/psychedelics such as LSD and psilocybin regarding cultural acceptance. LSD and psilocybin are usually associated with recreational use, which may limit their acceptance by a community that for decades have associated these drugs with mental health problems. Perhaps the example of ayahuasca use and regulation in South America could help to reduce the prejudice with other psychedelics. The public perception can change by the acceptance that a powerful mind-altering drug can be used respectfully by young and old community members, if used carefully. The recognition that psilocybin also has a deep history of medicinal and traditional use in Mexico could also help reducing the prejudice against its use. The mystical-type experiences that these compounds may produce help our understanding of their traditional medicinal 
uses and point to new, more respectful uses and perceptions of such uses.

The popularization and globalization of practices involving ayahuasca and other ethnobotanicals (like peyote, San Pedro or iboga - an African plant containing ibogaine) that occur outside of biomedical or culturally oriented settings and that are led by non-health professionals or unprepared individuals brings some important challenges that will be discussed in the next section.

\section{Healthcare Policy Challenges}

The opportunities offered by psychedelics/hallucinogens are accompanied by several challenges. One of the most relevant is the legal status of these compounds worldwide. Psilocybin, DMT, LSD, and MDMA are in the Schedule 1 of the United Nations Convention on Psychotropic Substances from 1971. This means that they lack therapeutic effects and have a high potential for abuse/dependence and to cause serious adverse effects. This often translates in costly and time-consuming bureaucratic processes to perform both preclinical and human studies with these drugs (if the studies are allowed at all to be performed at the end of this process). In this scenario, some researchers suggested that these drugs should be reclassified so that their therapeutic potentials can be fully investigated like any other drug with therapeutic potentials. ${ }^{75,76}$ But although re-schedule would be desirable, the Convention already established that scheduled substances are only allowed precisely for scientific and medical purposes. Thus, these substances should be re-scheduled not only because their risk do not correspond with the specific schedule list where they are located but because the Convention already guarantees its medical and scientific uses. Indeed, there are already some interesting and practical possibilities to explore their medical uses. The most immediate way is allowing its medical use under compassionate use conditions. This is already happening with LSD, psilocybin, and MDMA in Switzerland, the United States, Canada, and other countries. ${ }^{77}$

From a legal and ethical point of perspective, when the scientific and medical uses allowed by the Convention are not guaranteed by individual countries, the Convention has been violated. This violation confronts directly with several human rights, including the Right to science, the Right to enjoy the highest attainable standard of physical and mental health, and the Right to enjoy the benefits of scientific progress and its applications. ${ }^{78}$ Such violations usually happen for socio-political reasons, since in our society these drugs are associated with the stigma of recreational misuse, health problems, and limited therapeutic value. $^{79,80}$ This is especially relevant for LSD, psilocybin, and MDMA. As described above, these compounds can be safely administered in controlled settings, and several therapeutic potentials do exist. ${ }^{7,10}$ Even recognizing their potential for abuse in the recreational context, populational studies have not found that they are related to mental health problems in most users. ${ }^{22,62}$ Instead, their use was associated with mental health benefits. ${ }^{63-65}$ The re-scheduling of these drugs could lead to an increase in both research and public acceptance if such research finds beneficial effects.

Moreover, since the Convention allows the medical use of psychedelics, medical doctors should also gain (indeed, regain) the control and capacity to use the medicines that they consider the best option for their patients according to their clinical criteria. It could also be understood as unethical that some patients need to wait to fail in several treatments before being treated with psychedelics. By rescheduling these compounds and following the already approved uses according to the Convention, many patients could obtain benefit from the treatment with these substances administered under medical conditions. Meanwhile, clinical trials will continue to be developed and performed to improve efficacy and safety.

The legal situation is also complex with ethnobotanicals. The only plants that are scheduled in the 1971 Convention are cannabis (Cannabis sativa), poppy (Papaver somniferum) and coca (Erythroxylum coca). Ayahuasca, peyote, iboga, and Psilocybe mushrooms are not scheduled. ${ }^{81}$ However, some countries have specific laws for controlling them, which often lead to criminal accusations against people carrying or using these plants. This controversial legal situation has been contested by several international social movements that demand that the Convention should be respected and that people carrying or using these plants should not suffer criminal accusations. Moreover, such social movements also demand the decriminalization of scheduled plants. For instance, some US States like Oregon and Colorado, and cities, such as Oakland or Denver, have already passed bills decriminalizing psychoactive plants. Furthermore, countries like Canada have already approved medical compassionate use with these plants and fungi.

In the specific case of ayahuasca, its ritual and therapeutic use by indigenous groups in several South American countries including Brazil, Colombia, Peru, 
and Ecuador is not scheduled and, indeed, is protected by local legislation. ${ }^{74}$ The same type of legal and cultural acceptance is observed among non-indigenous populations in these countries, including local healers from jungle/rural areas and organized groups in urban centers such as the Brazilian syncretic religions that use ayahuasca as their sacrament (Santo Daime, União do Vegetal, and Barquinha). Over the past 20 years, these Brazilian syncretic religions have spread throughout Latin America and to several countries, including the US, Canada, Japan, South Africa, Australia, and several European countries. ${ }^{74}$ In several of these places these groups have achieved some form of legal authorization for the ritual/ religious use of ayahuasca. Therefore, ayahuasca is different from LSD and psilocybin both regarding regulation and cultural acceptance, which can be more challenging in the case of LSD, psilocybin, MDMA, and other synthetic drugs related to drug abuse/misuse. Furthermore, specifically in the case of Brazil, the regulation that allows the Brazilian ayahuasca religions to use ayahuasca ritually also allows (and indeed stimulates) preclinical and clinical research with ayahuasca. ${ }^{74}$

This more permissive context in Brazil and South America with ayahuasca could probably facilitate its integration in broader healthcare systems. Maybe in the near future a dynamic and collaborative continuum ranging from the ritual and therapeutic uses in indigenous and religious groups to the psychiatric and psychotherapeutic uses in nonindigenous/-traditional societies could be achieved.

Another important healthcare policy challenge involves funding. Since these drugs were described several decades ago and/or are natural compounds (psilocybin, DMT, mescaline) they are usually considered off-patent. Furthermore, the paradigm of using single or few doses during treatment is often not considered financially attractive. Thus, until recent years, the pharmaceutical industry usually gave little support for such studies. Indeed, most of the current research with these drugs is funded by private and charitable donations. ${ }^{76}$ However, this scenario is rapidly changing, with several pharmaceutical companies being created and funding clinical trials with these drugs. For instance, several pharmaceutical companies are investing in developing psychedelics as prescription medicines. ${ }^{82}$ Examples of this increasing interest include the breakthrough therapy designation granted by the US Food and Drug Administration for the trials of psilocybin for major depression funded by the Usona Institute and for treatment-resistant depression funded by Compass Pathways/Atai. ${ }^{83}$ Again, ayahuasca is an exception. To the best of our knowledge, Brazil is not only the single country that is currently running clinical trials with ayahuasca but all these trials are funded by national and/or local public agencies that give financial support for research in the country.

Paradoxically, pharmaceutical companies are now using the knowledge accumulated in the preclinical and Phase 1 studies with LSD, psilocybin, and DMT/ayahuasca to develop their products. It is important to acknowledge that substances like psilocybin and ayahuasca/DMT were discovered and extracted from indigenous communities. Psychedelic pharmaceutical companies should think in terms of reciprocity to return both to society and to indigenous communities the benefits of their sales when psychedelic substances become prescription medicines. That would mean, for example, to facilitate these drugs for free to those medical doctors using them under the umbrella of compassionate use programs, and to invest and develop programs in indigenous and other traditional communities. Moreover, since the ritual and therapeutic use of ayahuasca is traditionally spread in South America and the plants used in its preparation are native to these countries, each country needs to follow its specific rules regulating the use of traditional knowledge and endemic genetic material. ${ }^{63}$

Another significant challenge is related to the different medical systems involved in psychedelic practices. While biomedical practices are validated by the means of clinical trials, traditional practices have already been validated by the long history of traditional use. Currently, we are in an unusual situation where the medicalization of psychedelics co-exists with community/traditional uses. For instance, the therapeutic use of ethnobotanicals by a mixture of mental health professionals, lay persons that have learned how to use them in traditional contexts, and a myriad of other practitioners and providers, are emerging all over the world. Due to globalization, traditional medical systems and scientific biomedical approaches already co-exist. Not only Western medical systems are exported to indigenous communities but traditional medical systems are gaining popularity in Western societies. Indigenous doctors are coming to Wester countries to perform ayahuasca/iboga rituals, while Westerners are traveling to Amazonian/ African countries in search of spiritual enlightenment and healing. Contemporary research is starting to show how traditional medical systems involving ayahuasca are helping Westerns to improve their mental and physical conditions. ${ }^{51,84}$ Moreover, the paradigm of the Right to science is also starting to recognize traditional knowledge 
as a special kind of scientific knowledge. ${ }^{78}$ In the future, the co-existence of such different systems will face the challenge of regulation. Ethical standards will need to be defined, professionals will need to be trained, and longterm safety will need to be monitored. The traditional use of ayahuasca could serve as an example of regulatory rigor while respecting traditional knowledge.

Other important challenges are the costs to implement such therapies and the feasibility and adherence of long therapeutic sessions. In the case of LSD and psilocybin, most therapeutic models being currently investigated involve a series of preparatory and integration sessions and the actual session, which is usually performed by several therapists. While this structure surely increases the safety of the process and may indeed increase its efficacy, it could be unrealistic to implement in society, especially in less economically developed countries.

Moreover, culturally adapted settings will need to be developed, since the therapeutic settings in studies made in the US and Europe are not necessarily efficient and accessible in other countries. Further, several therapy sessions will certainly increase treatment costs and reduce adherence, and the professionals involved in implementing those therapies will need to be trained. Thus, the scientific community could try to investigate more accessible forms of implementing those therapies.

\section{Conclusions}

Psychedelics or classic hallucinogens are promising substances to treat depression, anxiety, and substance-related disorders. The available evidence suggests that these drugs will be incorporated in health systems worldwide in the following years. Complex situations need complex solutions. Thus, more than never it will be necessary a dialogue between scientists, policy and decision makers, community agents, social and health professionals, spiritual leaders, ethnobotanical ceremony providers, and activists. ${ }^{78}$ There is no way to avoid the incorporation of psychedelics into Western societies both in the medical and in the social levels, so only progressive and regulating-oriented approaches (rather than repressive and persecution oriented) will be of benefit for society.

\section{Disclosure}

GNR received funding from Conselho Nacional de Desenvolvimento Científico e Tecnológico (CNPq, Brazil). JMR received funding from FAPESP (Fundação de Amparo à Pesquisa do Estado de São Paulo, Brazil). RGS is Fellow of the Programa Nacional de Pós-Doutorado, Brazil (PNPD/
CAPES). JEH is recipient of Conselho Nacional de Desenvolvimento Científico e Tecnológico (CNPq, Brazil) 1 A productivity fellowship. The authors declare no other conflicts of interest.

\section{References}

1. Nichols DE. Psychedelics. Pharmacol Rev. 2016;68(2):64-355. doi:10.1124/pr.115.011478

2. Nichols DE. Hallucinogens. Pharmacol Ther. 2004;101(2):131-181.

3. Escobar JÁ, Roazzi A. Panorama contemporâneo do uso terapêutico de substâncias psicodélicas: ayahuasca e psilocibina. Neurobiologia. 2010;73(3):159-172.

4. Grispoon L, Bakalar JB. Psychedelic Drugs Reconsidered. New York: Basic Books; 1979.

5. Schultes RE, Hofmann A. Plants of the Gods: Their Sacred, Healing, and Hallucinogenic Powers. Rochester: Healing Arts Press; 1992.

6. Ott J. Pharmacotheon: drogas enteogénicas, sus fuentes vegetales y su historia (Pharmacotheon: entheogenic drugs, their plant sources and history). La Liebre de Marzo, Barcelona; 2004. Spanish.

7. Dos Santos RG, Hallak JE. Therapeutic use of serotoninergic hallucinogens: a review of the evidence and of the biological and psychological mechanisms. Neurosci Biobehav Rev. 2020;108:423-434. doi:10.1016/j.neubiorev.2019.12.001

8. Bogenschutz MP, Ross S. Therapeutic applications of classic hallucinogens. Curr Topics Behav Neurosci. 2018;36:361-391.

9. Liechti ME, Dolder PC, Schmid Y. Alterations of consciousness and mystical-type experiences after acute LSD in humans. Psychopharmacology (Berl). 2017;234(9-10):1499-1510. doi:10.10 07/s00213-016-4453-0

10. Dos Santos RG, Bouso JC, Alcázar-Córcoles MÁ, Hallak JE. Efficacy, tolerability, and safety of serotonergic psychedelics for the management of mood, anxiety, and substance-use disorders: a systematic review of systematic reviews. Expert Rev Clin Pharmacol. 2018;11:889-902. doi:10.1080/17512433.2018.1511424

11. Timmermann C, Roseman L, Williams L, et al. DMT models the near-death experience. Front Psychol. 2018;9. doi:10.3389/fpsyg. 2018.01424

12. Johnson M, Richards W, Griffiths R. Human hallucinogen research: guidelines for safety. $J$ Psychopharmacol. 2008;22(6):603-620. doi:10.1177/0269881108093587

13. Dos Santos RG, Osório FL, Crippa JA, Hallak JE. Antidepressive and anxiolytic effects of ayahuasca: a systematic literature review of animal and human studies. Rev Bras Psiquiatr. 2016a;38:65-72. doi:10.1590/1516-4446-2015-1701

14. Barker SA. N, N-dimethyltryptamine (DMT), an endogenous hallucinogen: past, present, and future research to determine its role and function. Front Neurosci. 2018;12:536. doi:10.3389/fnins.2018.00536

15. Cohen S. The Beyond Within, the LSD Story. New York: Atheneum; 1967.

16. Carhart-Harris RL, Nutt DJ. Serotonin and brain function: a tale of two receptors. J Psychopharmacol. 2017;31(9):1091-1120. doi:10.11 77/0269881117725915

17. Davis AK, Barrett FS, May DG, et al. Effects of psilocybin-assisted therapy on major depressive disorder: a randomized clinical trial. JAMA Psychiatry. 2020. doi:10.1001/jamapsychiatry.2020.3285

18. Griffiths RR, Johnson MW, Carducci MA, et al. Psilocybin produces substantial and sustained decreases in depression and anxiety in patients with life-threatening cancer: a randomized double-blind trial. J Psychopharmacol. 2016;30(12):1181-1197. doi:10.1177/0269881116675513

19. Ross S, Bossis A, Guss J, et al. Rapid and sustained symptom reduction following psilocybin treatment for anxiety and depression in patients with life-threatening cancer: a randomized controlled trial. J Psychopharmacol. 2016;30(12):1165-1180. doi:10.1177/026988 1116675512 
20. Bogenschutz MP, Forcehimes AA, Pommy JA, Wilcox CE, Barbosa PC, Strassman RJ. Psilocybin-assisted treatment for alcohol dependence: a proof-of-concept study. J Psychopharmacol. 2015;29 (3):289-299. doi:10.1177/0269881114565144

21. Johnson MW, Garcia-Romeu A, Cosimano MP, et al. Pilot study of the 5-HT2A agonist psilocybin in the treatment of tobacco addiction. J Psychopharmacol. 2014;28(11):983-992. doi:10.1177/0269881114 548296

22. Krebs TS, Johansen PØ. Psychedelics and mental health: a population study. PLoS One. 2013;8(8):e63972. doi:10.1371/journal.pone.0063972

23. Gasser P, Holstein D, Michel Y, et al. Safety and efficacy of lysergic acid diethylamide-assisted psychotherapy for anxiety associated with life-threatening diseases. J Nerv Ment Dis. 2014;202(7):513-520. doi:10.1097/NMD.0000000000000113

24. Dos Santos RG, Landeira-Fernandez J, Strassman RJ, et al. Effects of ayahuasca on psychometric measures of anxiety, panic-like and hopelessness in Santo Daime members. J Ethnopharmacol. 2007;112 (3):507-513. doi:10.1016/j.jep.2007.04.012

25. Sanches RF, De Lima Osório F, Dos Santos RG, et al. Antidepressant effects of a single dose of ayahuasca in patients with recurrent depression: a SPECT study. J Clin Psychopharmacol. 2016;36 (1):77-81. doi:10.1097/JCP.0000000000000436

26. Palhano-Fontes F, Barreto D, Onias H, et al. Rapid antidepressant effects of the psychedelic ayahuasca in treatment-resistant depression: a randomized placebo-controlled trial. Psychol Med. 2019;49 (4):655-663. doi:10.1017/S0033291718001356

27. Zeifman RJ, Palhano-Fontes F, Hallak J, Arcoverde E, Maia-Oliveira JP, Araujo DB. The impact of ayahuasca on suicidality: results from a randomized controlled trial. Front Pharmacol. 2019;10:1325. doi:10.3389/fphar.2019.01325

28. Zeifman RJ, Singhal N, Dos Santos RG, et al. Rapid and sustained decreases in suicidality following a single dose of ayahuasca among individuals with recurrent major depressive disorder: results from an open-label trial. Psychopharmacology (Berl). 2020;238(2):453-459. doi:10.1007/s00213-020-05692-9

29. Nichols DE. Differences between the mechanism of action of MDMA, MBDB, and the classic hallucinogens. Identification of a new therapeutic class: entactogens. $J$ Psychoactive Drugs. 1986;18(4):305-313. doi:10.1080/02791072.1986.10472362

30. Danforth AL, Grob CS, Struble C, et al. Reduction in social anxiety after MDMA-assisted psychotherapy with autistic adults: a randomized, double-blind, placebo-controlled pilot study. Psychopharmacology (Berl). 2018;235(11):3137-3148. doi:10.1007/ s00213-018-5010-9

31. Mithoefer MC, Mithoefer AT, Feduccia AA, et al. 3,4-methylenedioxymethamphetamine (MDMA)-assisted psychotherapy for post-traumatic stress disorder in military veterans, firefighters, and police officers: a randomised, double-blind, dose-response, Phase 2 clinical trial. Lancet Psychiatry. 2018;5(6):486-497. doi:10.1016/ S2215-0366(18)30135-4

32. Reiff CM, Richman EE, Nemeroff CB, et al. Psychedelics and psychedelic-assisted psychotherapy. Am J Psychiatry. 2020;177 (5):391-410. doi:10.1176/appi.ajp.2019.19010035

33. de la Torre R, Farré M, Roset PN, et al. Human pharmacology of MDMA: pharmacokinetics, metabolism, and disposition. Ther Drug Monit. 2004;26(2):137-144. doi:10.1097/00007691-2004040 00-00009

34. Nardou R, Lewis EM, Rothhaas R, et al. Oxytocin-dependent reopening of a social reward learning critical period with MDMA. Nature. 2019;569(7754):116-120. doi:10.1038/s41586-019-1075-9

35. Feduccia AA, Mithoefer MC. MDMA-assisted psychotherapy for PTSD: are memory reconsolidation and fear extinction underlying mechanisms?. Prog Neuropsychopharmacol Biol Psychiatry. 2018;84:221-228. doi:10.1016/j.pnpbp.2018.03.003
36. Vollenweider FX, Leenders KL, Scharfetter C, et al. Positron emission tomography and fluorodeoxyglucose studies of metabolic hyper frontality and psychopathology in the psilocybin model of psychosis. Neuro Psychopharmacol. 1998;16(5):357-372. doi:10.1016/S0893133X(96)00246-1

37. Preller KH, Herdener M, Pokorny T, et al. The fabric of meaning and subjective effects in LSD-induced states depend on serotonin 2A receptor activation. Curr Biol. 2017;27(3):451-457. doi:10.1016/j. cub.2016.12.030

38. Rickli A, Moning OD, Hoener MC, et al. Receptor interaction profiles of novel psychoactive tryptamines compared with classic hallucinogens. Eur Neuropsychopharmacol. 2016;26(8):1327-1337. doi:10.1016/j.euroneuro.2016.05.001

39. Marek GJ. Interactions of hallucinogens with the glutamatergic system: permissive network effects mediated through cortical layer V pyramidal neurons. Curr Top Behav Neurosci. 2018;36:107-135.

40. Bouso JC, Fábregas JM, Antonijoan RM, et al. Acute effects of ayahuasca on neuropsychological performance: differences in executive function between experienced and occasional users. Psychopharmacology. 2013;230(3):415-424. doi:10.1007/s00213-013-3167-9

41. Ly C, Greb AC, Cameron LP, et al. Psychedelics promote structural and functional neural plasticity. Cell Rep. 2018;23(11):3170-3182. doi:10.1016/j.celrep.2018.05.022

42. Carhart-Harris RL, Leech R, Hellyer PJ, et al. The entropic brain: a theory of conscious states informed by neuroimaging research with psychedelic drugs. Front Hum Neurosci. 2014;8:20. doi:10.3389/ fnhum.2014.00020

43. Palhano-Fontes F, Andrade KC, Tofoli LF, et al. The psychedelic state induced by ayahuasca modulates the activity and connectivity of the default mode network. PLoS One. 2015;10(2):e0118143. doi:10.1371/journal.pone.0118143

44. Pasquini L, Palhano-Fontes F, Araujo DB. Subacute effects of the psychedelic ayahuasca on the salience and default mode networks. $J \quad$ Psychopharmacol. 2020;34(6):623-635. doi:10.1177/0269881120 909409

45. Galvao ACM, de Almeida RN, Silva E, et al. Cortisol modulation by ayahuasca in patients with treatment resistant depression and healthy controls. Front Psychiatry. 2018;9:185. doi:10.3389/fpsyt.2018.00185

46. de Almeida RN, Galvao ACM, da Silva FS, et al. Modulation of serum brain-derived neurotrophic factor by a single dose of ayahuasca: observation from a randomized controlled trial. Front Psychol. 2019;10:1234. doi:10.3389/fpsyg.2019.01234

47. Galvao-Coelho NL, de Menezes Galvao AC, de Almeida RN, et al. Changes in inflammatory biomarkers are related to the antidepressant effects of Ayahuasca. J Psychopharmacol. 2020;34(10):1125-1133. doi: $10.1177 / 0269881120936486$

48. De araujo DB, Ribeiro S, Cecchi GA, et al. Seeing with the eyes shut: neural basis of enhanced imagery following Ayahuasca ingestion. Hum Brain Mapp. 2012;33(11):2550-2560. doi:10.1002/hbm.21381

49. Rocha JM, Osório FL, Crippa JA, et al. Serotonergic hallucinogens and recognition of facial expressions. Therapy $A d v$ Psychopharmacol. 2019;9:2045125319845774. doi:10.1177/ 2045125319845774.

50. Kometer M, Schmidt A, Bachmann R, et al. Psilocybin biases facial recognition, goal-directed behavior, and mood state toward positive relative to negative emotions through different serotonergic sub receptors. Biol Psychiatry. 2012;72(11):898-906. doi:10.1016/j. biopsych.2012.04.005

51. Gonzalez D, Cantillo J, Perez I, et al. Therapeutic potential of ayahuasca in grief: a prospective, observational study. Psychopharmacology (Berl). 2020;237(4):1171-1182. doi:10.1007/s00213-019-05446-2

52. Sampedro F, Revenga MF, Valle M, Roberto N, Domínguez-Clavé E, Elices M. Assessing the psychedelic "after-glow" in ayahuasca users: post-acute neurometabolic and functional connectivity changes are associated with enhanced mindfulness capacities. Int $J$ Neuropsychopharmacol. 2017;20(9):698-711. doi:10.1093/ijnp/pyx036 
53. Soler J, Elices M, Franquesa A, et al. Exploring the therapeutic potential of Ayahuasca: acute intake increases mindfulness-related capacities. Psychopharmacology (Berl). 2016;233(5):823-829. doi:10.1007/s00213-015-4162-0

54. Soler J, Elices M, Dominguez-Clave E, et al. Four weekly Ayahuasca sessions lead to increases in "Acceptance" capacities: a comparison study with a standard 8 -week mindfulness training program. Front Pharmacol. 2018;9:224. doi:10.3389/fphar.2018.00224

55. Franquesa A, Sainz-Cort A, Gandy S, Soler J, Alcazar-Corcoles MA, Bouso JC. Psychological variables implied in the therapeutic effect of ayahuasca: a contextual approach. Psychiatry Res. 2018;264: 334-339. doi:10.1016/j.psychres.2018.04.012

56. Aixalà M, dos Santos RG, Hallak JEC, Bouso JC. Psychedelics and personality. ACS Chem Neurosci. 2018;9(10):2304-2306. doi:10.10 21/acschemneuro.8b00237

57. Bouso JC, Dos Santos RG, Alcázar-Córcoles MA, et al. Serotonergic psychedelics and personality: a systematic review of contemporary research. Neurosci Biobehav Rev. 2018;87:118-132. doi:10.1016/j. neubiorev.2018.02.004

58. Gøtzsche PC. Deadly Psychiatry and Organised Denial. People's Press; 2015.

59. Jerome L, Feduccia AA, Wang JB, et al. Long-term follow-up outcomes of MDMA-assisted psychotherapy for treatment of PTSD: a longitudinal pooled analysis of six phase 2 trials. Psychopharmacology (Berl). 2020;237(8):2485-2497. doi:10.1007/ s00213-020-05548-2

60. Morales-Garcia JA, Calleja-Conde J, Lopez-Moreno JA, et al. N, $\mathrm{N}$-dimethyltryptamine compound found in the hallucinogenic tea ayahuasca, regulates adult neurogenesis in vitro and in vivo. Transl Psychiatry. 2020;10(1):1-14. doi:10.1038/s41398-020-01011-0

61. Oña G, Bouso JC. Psychedelic drugs as a long-needed innovation in psychiatry. Qeios. 2020. doi:10.32388/T3EM5E.2

62. Johansen P- $\varnothing$, Krebs TS. Psychedelics not linked to mental health problems or suicidal behavior: a population study. J Psychopharmacol. 2015;29(3):270-279. doi:10.1177/0269881114568039

63. Ona G, Kohek M, Massaguer T, et al. Ayahuasca and public health: health status, psychosocial well-being, lifestyle, and coping strategies in a large sample of ritual ayahuasca users. J Psychoactive Drugs. 2019;51:135-145. doi:10.1080/02791072.2019.1567961

64. Jiménez-Garrido DF, Gómez-Sousa M, Ona G, et al. Effects of ayahuasca on mental health and quality of life in naïve users: a longitudinal and cross-sectional study combination. Sci Rep. 2020;10:4075. doi:10.1038/s41598-020-61169-x

65. Hendricks PS, Thorne CB, Clark CB, Coombs DW, Johnson MW. Classic psychedelic use is associated with reduced psychological distress and suicidality in the United States adult population. J Psychopharmacol. 2015;29(3):280-288. doi:10.1177/0269881114565653

66. Berman RM, Cappiello A, Anand A, et al. Antidepressant effects of ketamine in depressed patients. Biol Psychiatry. 2000;47(4):351-354. doi:10.1016/S0006-3223(99)00230-9

67. Jauhar S, Morrison P. Esketamine for treatment resistant depression. BMJ. 2019;366:155-72.
68. Dos Santos RG, Grasa E, Valle M, et al. Pharmacology of ayahuasca administered in two repeated doses. Psychopharmacology. 2012;219:1039-1053. doi:10.1007/s00213-011-2434-x

69. Fábregas JM, González D, Fondevila S, et al. Assessment of addiction severity among ritual users of ayahuasca. Drug Alcohol Depend. 2010;111(3):257-261. doi:10.1016/j.drugalcdep.2010.03.024

70. Rodd R. Reassessing the cultural and psychopharmacological significance of Banisteriopsis caapi: preparation, classification and use among the Piaroa of Southern Venezuela. J Psychoactive Drugs. 2008;40(3):301-307. doi:10.1080/02791072.2008.10400645

71. Kjellgren A, Eriksson A, Norlander T. Experiences of encounters with ayahuasca-"the vine of the soul". J Psychoactive Drugs. 2009;41(4):309-315. doi:10.1080/02791072.2009.10399767

72. Labate BC, MacRae E, editors. Ayahuasca, Ritual and Religion in Brazil. London: Equinox; 2010

73. Luna LE. Indigenous and mestizo use of Ayahuasca: an overview. In: Dos Santos RG, editor. The Ethnopharmacology of Ayahuasca. Trivandrum: Transworld Research Network; 2011.

74. Labate BC, Feeney K. Ayahuasca and the process of regulation in Brazil and internationally: implications and challenges. Int $J$ Drug Policy. 2012;23(2):154-161. doi:10.1016/j.drugpo.2011.06.006

75. Rucker JJ. Psychedelic drugs should be legally reclassified so that researchers can investigate their therapeutic potential. BMJ. 2015;350:h2902. doi:10.1136/bmj.h2902

76. Sessa B. Turn on and tune in to evidence-based psychedelic research. Lancet Psychiatry. 2015;2(1):10-12. doi:10.1016/S2215-0366(14) 00120-5

77. Schmid Y, Gasser P, Oehen P, Liechti ME. Acute subjective effects in LSD- and MDMA-assisted psychotherapy. J Psychopharmacol. 2020;026988112095960. doi:10.1177/0269881120959604

78. Bouso JC, Sánchez-Avilés C. Traditional healing practices involving psychoactive plants and the global mental health agenda: opportunities, pitfalls, and challenges in the "right to science" framework. Perspect Mental Health Human Rights. 2020;22(1):145-150.

79. Bonson KR. Regulation of human research with LSD in the United States (1949-1987). Psychopharmacology (Berl). 2018;235 (2):591-604. doi:10.1007/s00213-017-4777-4

80. Richert L, Dyck E. Psychedelic crossings: American mental health and LSD in the 1970s. Med Humanit. 2020;46(3):184-191. doi:10.1136/medhum-2018-011593

81. Sánchez C, Bouso JC. Drug Policy Briefing: ayahuasca: from the Amazon to the Global Village. Drug Policy Briefing. 2015.

82. Global psychedelic therapeutics market, 2020-2030 [homepage on the Internet]. Available from: https://www.rootsanalysis.com/reports/globalpsychedelic-therapeutics-market.html. Accessed November 20, 2020.

83. Bauer B. Usona follows COMPASS in receiving breakthrough therapy designation for psilocybin to treat depression. Psychedelic Sci Rev. 2019.

84. Berlowitz I, Walt H, Ghasarian C, O'shaughnessy DM, Mabit EJ, Rush FB. Who turns to Amazonian medicine for treatment of substance use disorder? Patient characteristics at the Takiwasi addiction treatment center. J Stud Alcohol Drugs. 2020;81(4):416-425. doi:10.15288/jsad.2020.81.416 


\section{Publish your work in this journal}

Risk Management and Healthcare Policy is an international, peerreviewed, open access journal focusing on all aspects of public health, policy, and preventative measures to promote good health and improve morbidity and mortality in the population. The journal welcomes submitted papers covering original research, basic science, clinical \& epidemiological studies, reviews and evaluations, guidelines, expert opinion and commentary, case reports and extended reports. The manuscript management system is completely online and includes a very quick and fair peer-review system, which is all easy to use. Visit http://www.dovepress.com/testimonials.php to read real quotes from published authors. 